\title{
Hybrid layer-by-layer (LbL) films of polyaniline, graphene oxide and zinc oxide to detect ammonia
}

\author{
Rafaela S. Andre ${ }^{\mathrm{a}, \mathrm{b}, *}$, Flávio M. Shimizu ${ }^{\mathrm{a}, \mathrm{c}}$, Celina M. Miyazaki ${ }^{\mathrm{d}}$, Antonio Riul Jr${ }^{\mathrm{e}}$, \\ Danilo Manzani ${ }^{\mathrm{f}}$, Sidney J.L. Ribeiro ${ }^{\mathrm{f}}$, Osvaldo N. Oliveira Jr ${ }^{\mathrm{c}}$, Luiz H.C. Mattoso ${ }^{\mathrm{a}, \mathrm{b}}$, \\ Daniel S. Correa ${ }^{\mathrm{a}, \mathrm{b}, * *}$ \\ a National Laboratory for Nanotechnology in Agribusiness (LNNA), Embrapa Instrumentation, 13560-970, São Carlos, SP, Brazil \\ ${ }^{\mathrm{b}}$ Center for Exact Sciences and Technology, Department of Chemistry, Federal University of São Carlos (UFSCar), 13565-905, São Carlos, SP, Brazil \\ c São Carlos Institute of Physics (IFSC), University of Sa o Paulo (USP), P.O. Box 369, 13566-590 Sa o Carlos, SP, Brazil \\ d CCTS, Federal University of São Carlos (UFSCar), Sorocaba, SP, Brazil \\ e Institute of Physics Gleb Wataghin, Unicamp, 13083-859, Campinas, SP, Brazil \\ ${ }^{\mathrm{f}}$ Institute of Chemistry, São Paulo State University (UNESP), 14801-970, Araraquara, SP, Brazil
}

\section{A R T I C L E I N F O}

\section{Article history:}

Received 22 February 2016

Received in revised form 17 July 2016

Accepted 19 July 2016

Available online 20 July 2016

\section{Keywords:}

Ammonia sensor

Graphene oxide

Polyaniline

Impedance spectroscopy

Nanostructured film

\begin{abstract}
A B S T R A C T
Reliable gas sensors operating at room temperature are in demand for monitoring the environment for hazardous pollutants, such as ammonia $\left(\mathrm{NH}_{3}\right)$ gas that may become toxic to humans and animals above a threshold concentration. In this paper we report on the combination of three materials, namely polyaniline (PANI), graphene oxide (GO) and zinc oxide ( $\mathrm{ZnO}$ ), to produce hybrid layer-by-layer (LbL) films used for sensing $\mathrm{NH}_{3}$ with impedance spectroscopy measurements. The deposition of tetralayered PANI/GO/PANI/ZnO LbL films was confirmed with UV-vis. absorption and Raman spectroscopies, while atomic force microscopy (AFM) served to investigate film morphology. Exposure of these LbL films to $\mathrm{NH}_{3}$ caused film roughness to vary, in an effect that depended on the number of tetralayers. Because of synergy in the materials properties, the films with 3 tetralayers were found to be the most adequate for detecting $\mathrm{NH}_{3}$ in the range from $25 \mathrm{ppm}$ to $500 \mathrm{ppm}$ with a response time of $30 \mathrm{~s}$. These figures of merit are adequate for monitoring working environments regarding gas exposure, and highlight the usefulness of the control of film architecture provided by the LbL technique.
\end{abstract}

(c) 2016 Elsevier B.V. All rights reserved.

\section{Introduction}

Sensitive, reliable gas sensors have great importance in medical applications, air quality supervision and environmental, health and safety monitoring [1-8]. Ammonia is a colourless gas used in many industries, which may become toxic and affect the health of humans and animals, such as in poultry farms $[9,10]$. For instance, $100-200 \mathrm{ppm}$ of ammonia induce drowsiness, salivation and loss of appetite in humans $[11,12]$. According to the regulatory agency in Brazil, the ammonia exposure level at working places should not exceed $20 \mathrm{ppm}$ within $48 \mathrm{~h} /$ week [13], while in England the ammonia exposure should not exceed $25 \mathrm{ppm}$ in $8 \mathrm{~h}$ [14]. The human

\footnotetext{
* Corresponding author at: National Laboratory for Nanotechnology in Agribusiness (LNNA), Embrapa Instrumentation, 13560-970, São Carlos, SP, Brazil.

** Corresponding author at: National Laboratory for Nanotechnology in Agribusiness (LNNA), Embrapa Instrumentation, 13560-970, São Carlos, SP, Brazil.

E-mail addresses: rafaela.s.a@outlook.com (R.S. Andre), daniel.correa@embrapa.br (D.S. Correa).
}

olfactory limit of detection for ammonia is $55 \mathrm{ppm}$, but loss of sensitivity occurs after long and repeated exposure [15-17]. Therefore, designing robust ammonia sensors with low limits of detection is necessary to increase safety and health in such environments [18]. The working principle of gas sensors can be based in changes of electrical and optical properties, with those exploiting electrical signal variations the most used since stable and reproducible sensors can be fabricated [19]. In particular, a myriad of materials can be exploited to achieve such task, including metal oxide semiconductors, conducting polymers, composite materials, carbon nanotubes and their derivatives [4,18,20-24].

In this paper, we report on sensing units made with nanostructured layer-by-layer (LbL) films [25-30] containing the semiconducting polyaniline (PANI), graphene oxide (GO) and zinc oxide ( $\mathrm{ZnO})$, all of them already used in sensing applications. The main motivation is to rationally combine different materials in a single device originated from a possible synergy of the materials properties. PANI has unique electrical behavior, easy fabrication process and intrinsic redox reaction [31-37]. ZnO has remarkable 


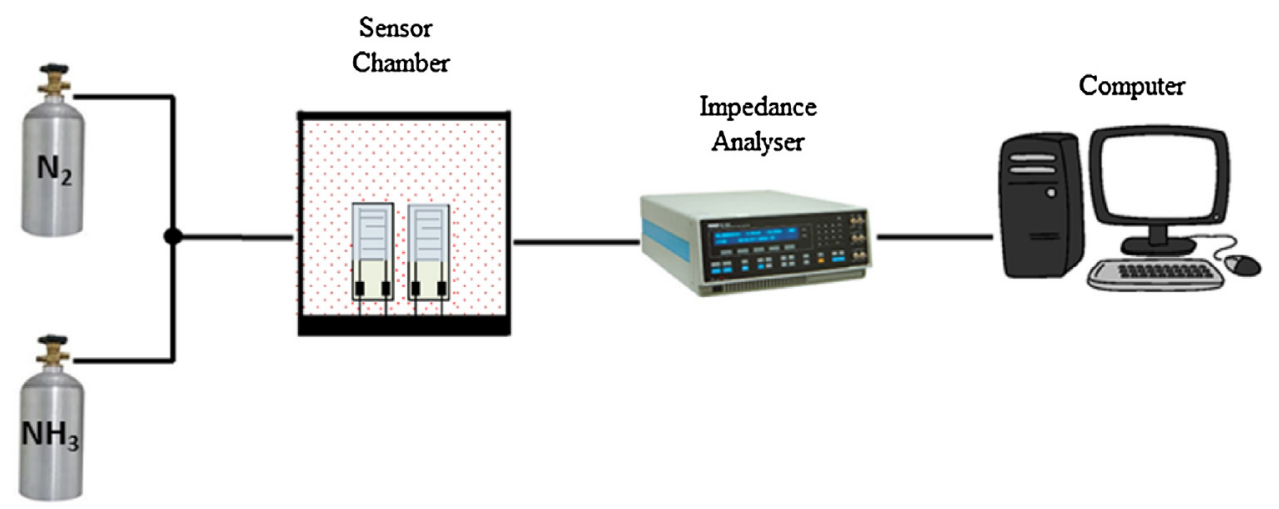

Fig. 1. Schematic diagram of the experimental setup for $\mathrm{NH}_{3}$ detection.

semiconducting properties [38-41], and GO has a porous structure, high surface area and good gas barrier properties [42-44]. Different LbL film architectures were tested for $\mathrm{NH}_{3}$ sensing using impedance spectroscopy, which were also characterized using UV-vis absorption spectroscopy, scanning electron microscopy, atomic force microscopy and Raman spectroscopy.

\section{Experimental}

\subsection{Materials}

Polyaniline (PANI, Mw $=20.000 \mathrm{~g} \mathrm{~mol}^{-1}$ ) was purchased from Sigma-Aldrich. ZnO nanoparticles were synthesized using the coprecipitation method followed by hydrothermal treatment at $150^{\circ} \mathrm{C}$ for $1 \mathrm{~h}$ as described in Ref [45]. Graphene oxide (GO) was prepared by typical Hummers' method [46] with a previous preoxidation step [47]. The dispersing agent Liosperse 511 was purchased from Miracema-Nuodex (Campinas, Brazil). Gold interdigitated microelectrodes (IDEs) comprising 50 pairs of digits having $10 \mu \mathrm{m}$ width and $10 \mu \mathrm{m}$ apart from each other were fabricated by photolithography at the Brazilian Nanotechnology National Laboratory (LNNano).

\subsection{Preparation of PANI/GO/PANI/ZnO LbL films}

PANI solution $(1 \mathrm{mg} / \mathrm{mL})$ was prepared by dispersing the emeraldine base in $1 \mathrm{~mL}$ of dimethylacetamide (DMAc) under stirring for $12 \mathrm{~h}$. The solution was then filtrated using a filter paper $\left(80 \mathrm{~g} / \mathrm{m}^{2}\right.$ and pores with $\left.8 \mu \mathrm{m}\right)$ purchased from J Prolab. Next, PANI solution was mixed with $\mathrm{HCl}$ excess $(1: 9 \mathrm{v}: \mathrm{v})$ at $\mathrm{pH}=3.0$. GO was dispersed similarly in $\mathrm{HCl}$ solution at $0.1 \mathrm{mg} \mathrm{mL}^{-1}(\mathrm{pH}=3.0)$. The dispersion of $\mathrm{ZnO}$ nanoparticles $\left(1 \mathrm{mgmL}^{-1}\right)$ was prepared using distilled water and the dispersing agent $(0.5 \%$ in relation to total volume) $(\mathrm{pH}=8.0$ ). Layer-by-Layer ( $\mathrm{LbL}$ ) films of PANI/GO/PANI/ZnO was deposited onto quartz plates and IDEs by sequential alternated immersions into PANI (cationic solution), GO (anionic solution), PANI and ZnO (anionic solution) until the formation of 2, 3 and 4 tetralayers (PGPZ2T, PGPZ3T and PGPZ4T).

\subsection{Multilayer films characterization}

The adsorption of LbL multilayers deposited on quartz slides was monitored by UV-vis absorption spectroscopy using a PerkinElmer Lambda 25 spectrometer. The morphology of the LbL films was evaluated using a scanning electron microscope (SEM, JEOL 6510 ) operating at $10 \mathrm{kV}$. The topography, roughness (root mean square value) and homogeneity of the LbL films were assessed by Atomic Force Microscopy (AFM) using a Dimension V (Veeco) microscope. The Raman spectra of the LbL films were taken at room

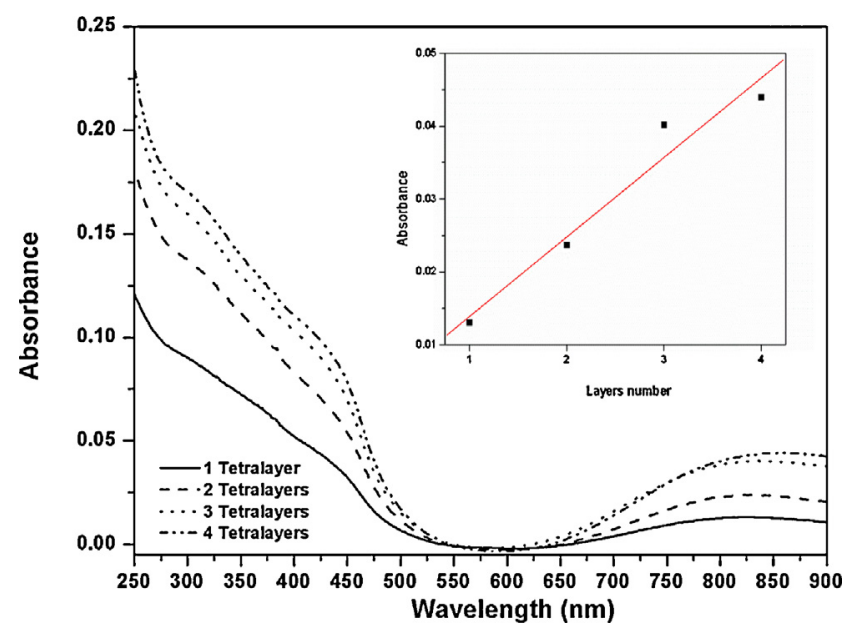

Fig. 2. Absorption spectra of LbL films (PGPZ2T, PGPZ3T and PGPZ4T). Inset displays the absorption peak intensity at $840 \mathrm{~nm}$ versus the number of deposited tetralayers.

temperature with a Horiba Jobin-Yvon micro Raman spectrometer model LabRAM-HR equipped with a $632.8 \mathrm{~nm}$ laser delivering $30 \mathrm{~mW}$.

\subsection{Electrical measurements}

Electrical characterization of the sensing units made with the LbL films deposited on IDEs was performed using an impedance analyzer (Solartron, model 1260). Data were collected in the frequency range from $1 \mathrm{~Hz}$ up to $1 \mathrm{MHz}$, using an ac applied voltage of $25 \mathrm{mV}$. The sensors were tested for $\mathrm{NH}_{3}$ detection, in concentrations ranging from $25 \mathrm{ppm}$ up to $500 \mathrm{ppm}$, in a closed chamber at room temperature $\left(24 \pm 2{ }^{\circ} \mathrm{C}\right)$ in relative humidity of $65 \pm 2 \%$ with a dynamic gas flow system in the homemade setup schematically displayed in Fig. 1. High purity $\mathrm{N}_{2}$ was used as carrying gas for $\mathrm{NH}_{3}$ flux.

\section{Results and discussion}

Fig. 2 shows the UV-vis spectra of tetralayered LbL films, with absorption bands at 320 and $840 \mathrm{~nm}$, assigned respectively to the $\pi-\pi^{*}$ electronic transition of the benzene ring of amine groups and $\pi-\pi^{*}$ transition of graphene (at approximately $290 \mathrm{~nm}$ ) [48], and polaronic band of doped PANI in its conductive emeraldine form [36]. The linear increase of the absorpion peak intensity at $840 \mathrm{~nm}$ with the number of tetralayers reveals that the same amount of material was deposited at each deposition step. 


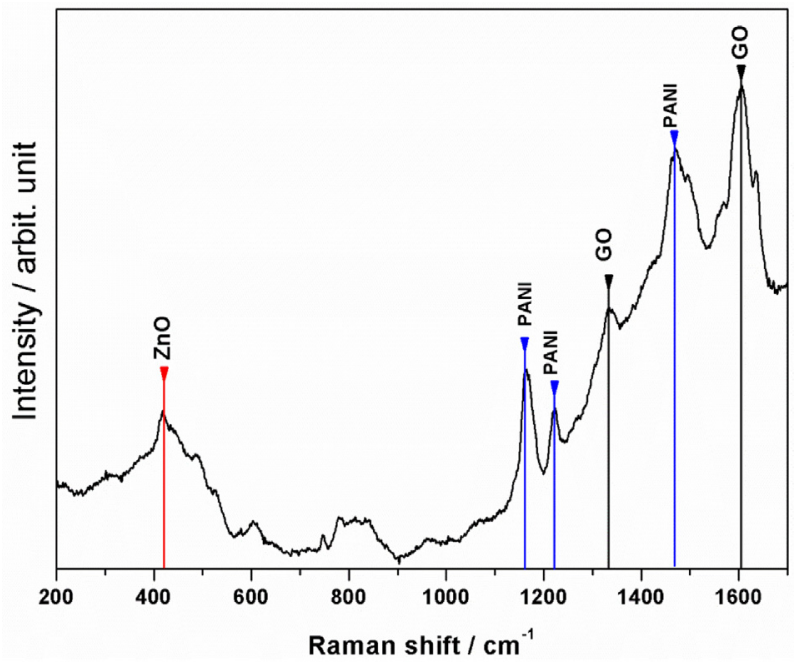

Fig. 3. Raman spectrum of PGPZ4T film.

Table 1

Parameters of the equivalent circuit used to fit the impedance data with ZView ${ }^{\circledR}$ software (Scribner Associates Inc.).

\begin{tabular}{lllll}
\hline Film & $\mathrm{R}_{1}(\Omega)$ & $\mathrm{R}_{2}(\Omega)$ & $\mathrm{C}_{1}(\mathrm{~F})$ & $\mathrm{QPE}_{1} \mathrm{n}$ \\
\hline PGPZ2T & 437.6 & 5524 & $8.78 \times 10^{-13}$ & 0.0832 \\
PGPZ3T & 460.5 & 2419 & $9.14 \times 10^{-11}$ & 0.0850 \\
PGPZ4T & 387.2 & 1133 & $1.23 \times 10^{-12}$ & 0.1410 \\
\hline
\end{tabular}

The presence of GO and PANI was inferred in the Raman spectrum in Fig. 3. The bands assigned to GO appear at $1333 \mathrm{~cm}^{-1}$ and $1604 \mathrm{~cm}^{-1}$, due to the breathing mode of k-point photons of $A_{1 g}$ symmetry and $E_{2 g}$ phonon of $\mathrm{sp}^{2}$ carbon atoms, respectively [48]. The PANI Raman bands appear at $1470 \mathrm{~cm}^{-1}$ assigned to $\mathrm{C}=\mathrm{N}$ stretching vibrations, while the band at $1222 \mathrm{~cm}^{-1}$ corresponds to $\mathrm{C}-\mathrm{N}$ stretching in polaronic units and at $1160 \mathrm{~cm}^{-1}$ assigned to $\mathrm{C}-\mathrm{H}$ in plane bending vibrations of benzenoid ring [24]. The $\mathrm{ZnO}$ nanoparticles show only one weak Raman band at $416 \mathrm{~cm}^{-1}$ assigned to phonons of $\mathrm{ZnO}$ compounds with hexagonal structures $[43,49]$.

The frequency dependence of the impedance real part ( $Z^{\prime}$ (ohms)) is shown in Fig. 4a for the three PGPZ LbL films with 2-4 tetralayers. The impedance spectra were fitted with an equivalent electrical circuit shown in Fig. $4 c$, comprising the resistor $\mathrm{R}_{1}$ representing the ohmic resistance from the interdigitated electrode (IDE), $R_{2}$ the film resistance and $C_{1}$ the capacitance of charge transfer across the multilayer film, in addition to a phase constant element that was included to improve fitting. The data in the form of Nyquist plots in Fig. $4 \mathrm{~b}$ for the three films in an inert atmosphere with $65 \%$ of humidity were fitted with the parameters displayed in Table 1. Both resistances decreased with the number of deposited tetralayers, possibly due to the increase in PANI amount since GO is insulating. A schematic representation of the PANI/GO/PANI/ZnO film deposited onto the IDE is displayed in Fig. 4(d).

The AFM images in Fig. 5 highlight two main features: i) before $\mathrm{NH}_{3}$ exposure, the film roughness increased with the number of tetralayers, from $35 \mathrm{~nm}$ (PGPZ2T) up to $52 \mathrm{~nm}$ (PGPZ4T); ii) after exposure to the $\mathrm{NH}_{3}$, film morphology was clearly affected. Specifically, the thinnest PGPZ2T film was probably deeply penetrated by ammonia, causing both dedoping of PANI and increase in surface roughness. On the other hand, the thicker films with larger amount of PANI had their roughness decreased after ammonia exposure, particularly for the thickest PGPZ4T, whose roughness decreased by $\sim 40 \%$. Significantly, Fig. 6 indicates that the PGPZ3T was only weakly affected by ammonia. It seems therefore that opposite a)

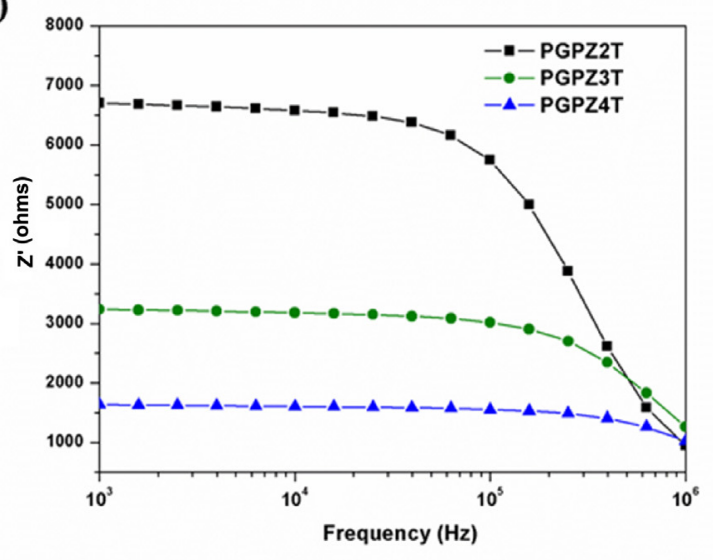

b)

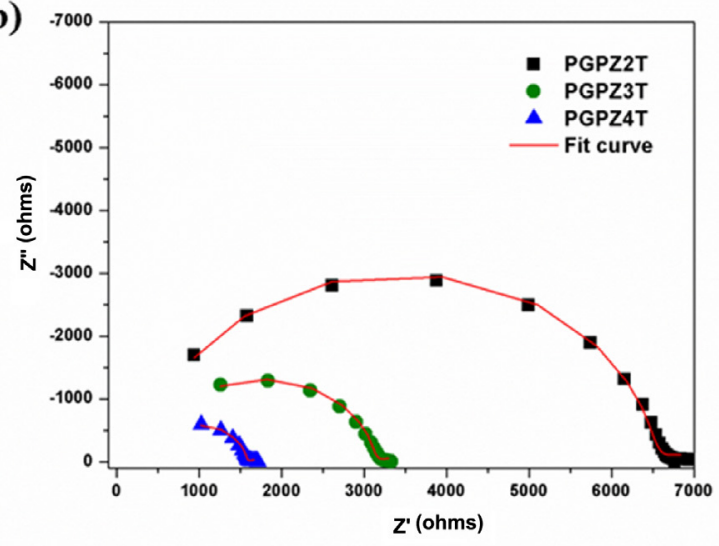

c)

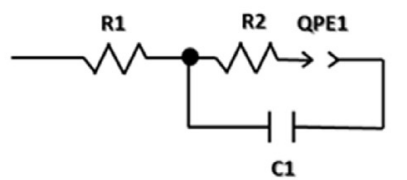

d)

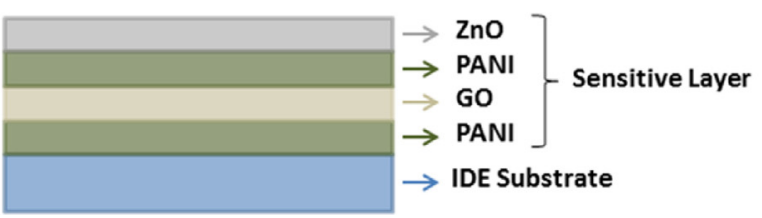

Fig. 4. a) real part of impedance ( $Z^{\prime}$ ) and b) Nyquist diagram for PGPZ2T, PGPZ3T and PGPZ4T films, c) equivalent circuit model and d) schematic representation of the PANI/GO/PANI/ZnO film deposited onto the IDE.

effects to alter film thickness occur for PGPZ3T, which is associated with synergy in the different materials properties. As it will be shown later, such synergy is responsible for the higher sensitivity of PGPZ3T.

The sensor units made of 2,3 and 4 tetralayers of $\mathrm{PANI} / \mathrm{GO} / \mathrm{PANI} / \mathrm{ZnO}$ were tested for detecting ammonia $\left(\mathrm{NH}_{3}\right)$ in a relative humidity $(\mathrm{RH})$ set as $65 \%$. The choice of this humidity value was made because previous investigations reported in the literature $[50,51]$ indicated that the ideal relative humidity in broiler poultry houses should range between 50 and $70 \%$; lower values 

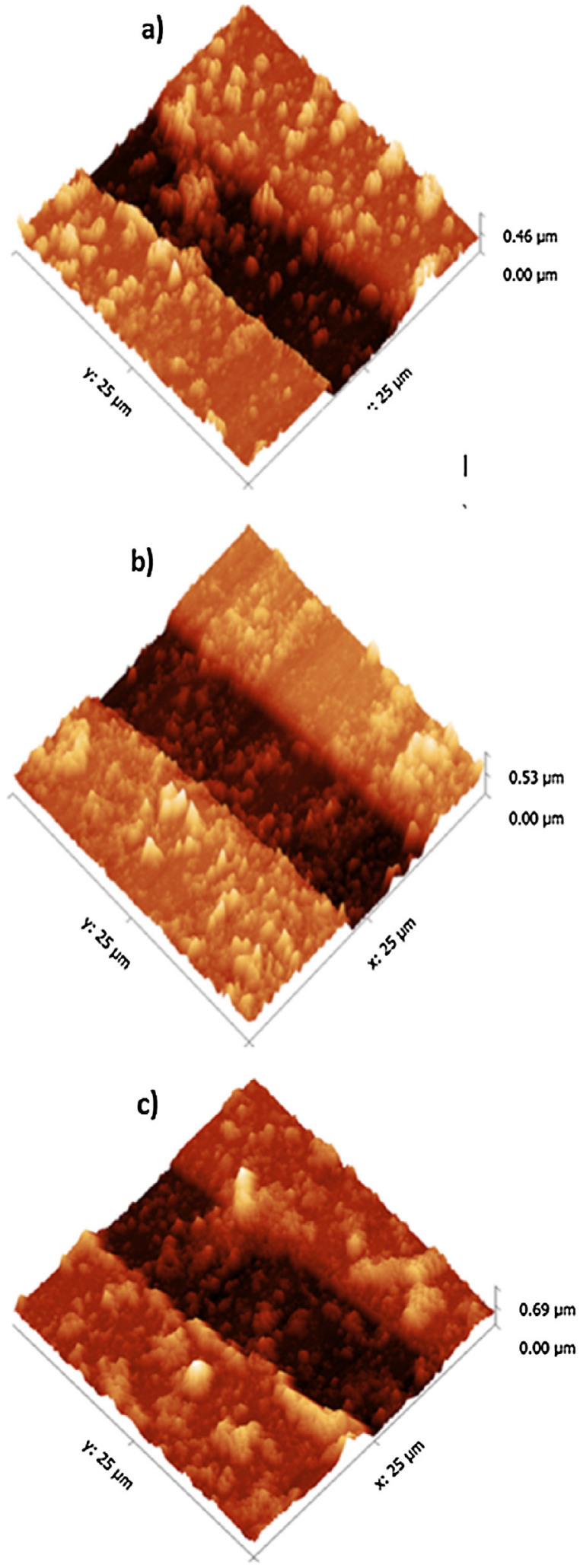

Fig. 5. AFM 3D images of a) PGPZ2T, b) PGPZ3T and c) PGPZ4T films.

can result in a dusty house, while higher values could result in wet litter and higher ammonia concentrations.

The relative response in terms of the impedance ratio (Eq. (1)) increased with $\mathrm{NH}_{3}$ concentration up to $500 \mathrm{ppm}$, as shown in Fig. 7a. PGPZ3T exhibited the most adequate response for all concentrations tested, which may be related to its morphology being

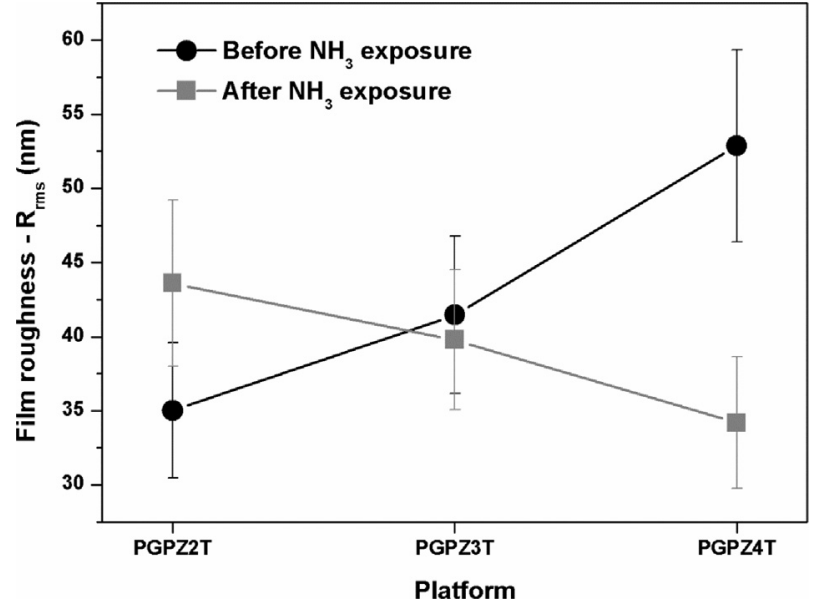

Fig. 6. Film roughness $\left(R_{\mathrm{rms}}\right)$ calculated using Gwyddion ${ }^{\circledR}$ software for LbL films (PGPZ2T, PGPZ3T and PGPZ4T) before and after exposure to ammonia gas.

less affected by ammonia, according to the AFM results, combined with the moderate resistive response of PANI/GO/PANI/ZnO sensitive layer (cf. Table 1). One would expect that the film with larger morphological changes upon $\mathrm{NH}_{3}$ exposure would yield the highest sensing performance. However, the sensing mechanism appears to depend on a combination of the charge transfer property of the three materials. ZnO $[18,52-55]$ is a $n$-type semiconductor and PANI is a semiconducting polymer, both allowing charge mobility that hinder formation of a stable double layer at the interface. In contrast, GO is an insulator that provides the stability needed for the charge transfer phenomenon in gas sensor application.

Response $=Z^{\prime}{ }_{\mathrm{NH}_{3}} / Z_{\text {air }}^{\prime}$

It should be noted that for low $\mathrm{NH}_{3}$ concentrations the sensing units exhibited similar responses, with low error associated to the measurements. That is an important issue to develop sensors able to detect $\mathrm{NH}_{3}$ below $50 \mathrm{ppm}$ [15-17]. In addition, the larger errors at higher concentrations of $\mathrm{NH}_{3}$ may be associated with the lower stability of the measuring system, since gas injection can cause small turbulences in the airflow system, as observed in the calibration curve of Fig. 7b. The response time for each $\mathrm{NH}_{3}$ concentration range was calculated using Eq. (2) to fit the calibration curve in Fig. 7b, leading to values ranging from 10 to $30 \mathrm{~s}$. It is worth mentioning that the fitting required the use of two exponential functions in Eq. (2), which points to more than one process ruling in the sensing mechanism.

$R(t)=y_{0}+A_{1}\left(1-e^{-t / t 1}\right)+A_{2}\left(1-e^{-t / t 2}\right)$

$\mathrm{R}(\mathrm{t})$ is the resistance as a function of time $(\mathrm{t}), \mathrm{y}_{0}, \mathrm{~A}_{1}$ and $\mathrm{A}_{2}$ are constants, and $t_{1}$ and $t_{2}$ are the response times.

Response times ranging values from 10 to $30 \mathrm{~s}$ are suitable for a device operating at room temperature, since $\mathrm{NH}_{3}$ gas diffusion and sensing usually occur in a time scale shorter than $30 \mathrm{~s}[20,56]$.

Statistical analysis of the impedance data was carried out using PEx-Sensors software[57-59], implementing multidimensional projection techniques. Here we used IDMAP (Interactive Document Map) with Euclidian distances between the data points and employing real impedance data dimensionally reduced by the Fastmap technique in the frequency range $10^{3}-10^{6} \mathrm{~Hz}$. The IDMAP plot in Fig. 8 confirms that all of the three sensors produced were effective to detect ammonia levels from 50 up to $500 \mathrm{ppm}$, with a combined silhouette coefficient of 0.64 (separate values of 0.60 for PGPZ2T, 0.59 for PGPZ3T and 0.54 for PGPZT4T), calculated according to Paulovich et. al [58]. With this quantitative measure of 
a)

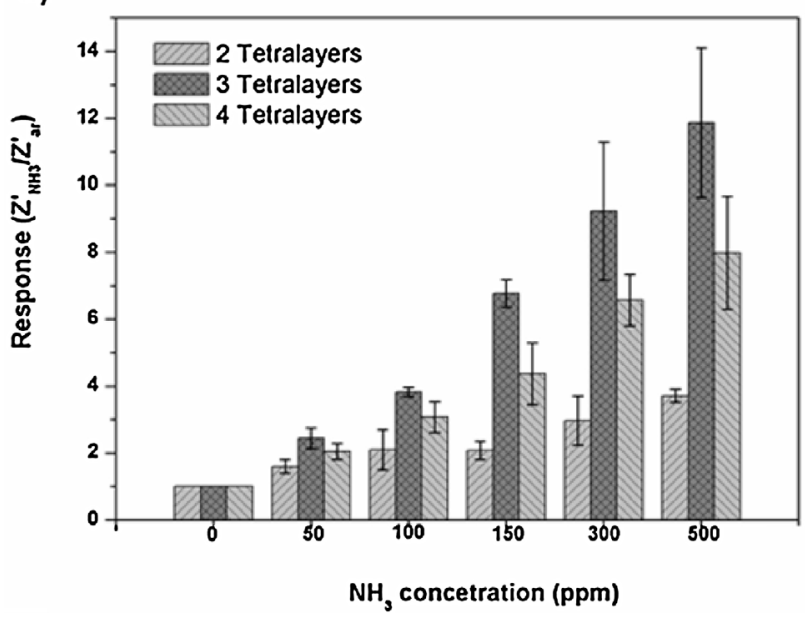

b)

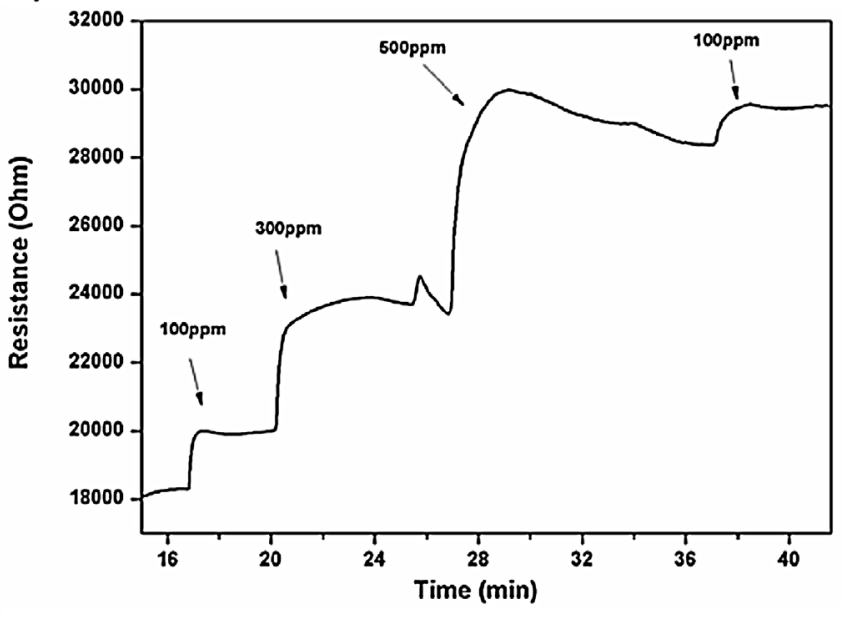

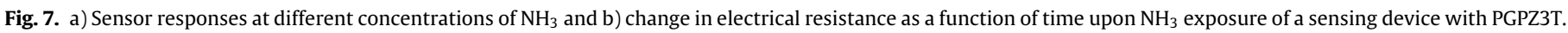

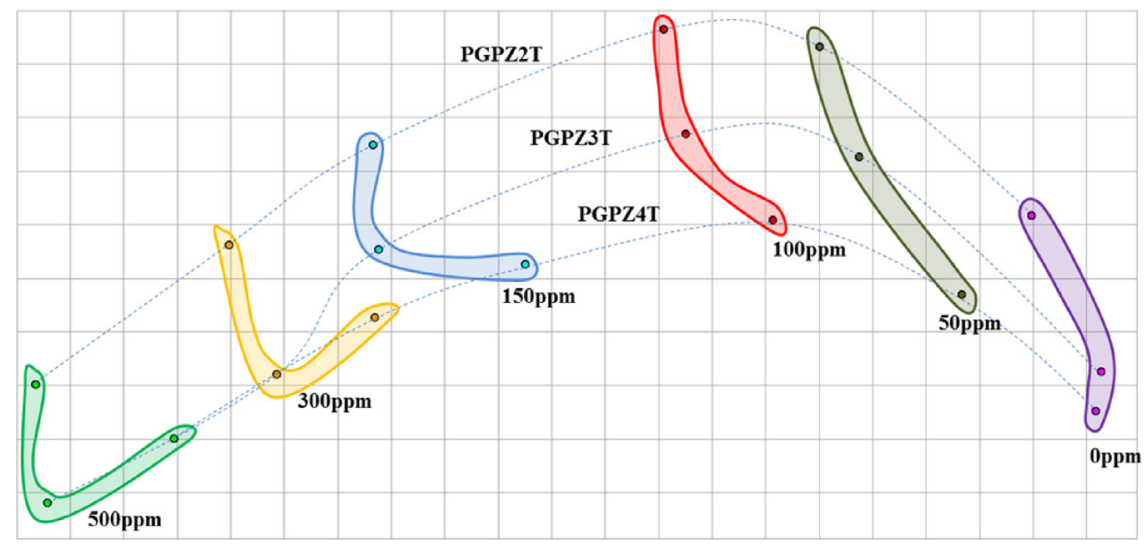

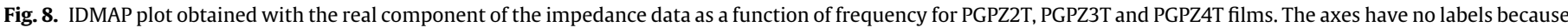

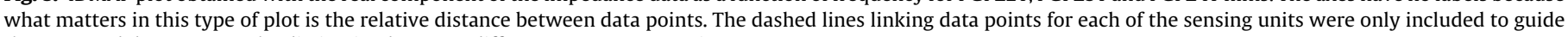
the eyes, and demonstrate the distinction between different $\mathrm{NH}_{3}$ concentrations.

Table 2

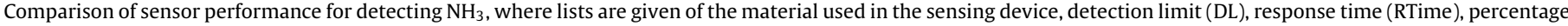
of response. The values quoted for PANI/GO/PANI/ZnO correspond to PGPZ3T.

\begin{tabular}{|c|c|c|c|c|}
\hline Material & Detection Limit (DL) & Response Time (RTime) & Response (\%) & Ref \\
\hline $\mathrm{PANI} / \mathrm{GO} / \mathrm{PANI} / \mathrm{ZnO}$ & $23 \mathrm{ppm}$ & $30 \mathrm{~s}(100 \mathrm{ppm})$ & 38.31 & This work \\
\hline PANI/GO & $1 \mathrm{ppm}$ & $50 \mathrm{~s}(100 \mathrm{ppm})$ & 11.33 & {$[20]$} \\
\hline $\mathrm{TiO}_{2} / \mathrm{PPy} / \mathrm{GN}$ & $1 \mathrm{ppm}$ & $36 \mathrm{~s}(50 \mathrm{ppm})$ & 36 & [63] \\
\hline $\mathrm{PANI} / \alpha \mathrm{Fe}_{2} \mathrm{O}_{3}$ & $5 \mathrm{ppm}$ & $27 \mathrm{~s}(100 \mathrm{ppm})$ & 39 & [64] \\
\hline $\mathrm{PPy} / \mathrm{SnO}_{2}$ & $257 \mathrm{ppb}$ & $259 \mathrm{~s}(5 \mathrm{ppm})$ & 30 & [65] \\
\hline $\mathrm{PANI} / \mathrm{SnO}_{2}$ & $1.8 \mathrm{ppm}$ & $34 \mathrm{~s}(100 \mathrm{ppm})$ & 29 & {$[66]$} \\
\hline
\end{tabular}

the discriminating power of a sensing device, PGPZ3T and PGPZ2T appear as the most adequate molecular architectures.

Regarding to ammonia sensors recently reported, Table 2 shows that the sensors made with tetralayered LbL films are competitive both in terms of response time and magnitude of the detection. Significantly, the figures of merit of the sensors presented here are an adequate choice for target applications, such as monitoring work places for excessive $\mathrm{NH}_{3}$ exposure. Furthermore, the sensor response remained stable up to 15 days, while a decay of $56 \%$ on response signal was observed 30 days later.

Although one should expect that a platform based solely on PANI and $\mathrm{ZnO}(\mathrm{PANI} / \mathrm{ZnO}$ ) combination could be adequate for sensing application, as PANI presents high sensitivity at room temperature [60] while ceramic materials may provide suitable response time for sensing application [24,61], this was not found to be the case. Subsidiary experiments (results not shown) employing solely PANI/ZnO platform (without GO) showed to be sensitive to $\mathrm{NH}_{3}$ but with a highly unstable electrical response, which is not adequate for gas sensing application. Therefore, the incorporation of GO to the nanostructured platform definitely improved the sensor response, which is consistent with findings of the literature [62]. Furthermore, PANI/GO/PANI/ZnO platform not only showed improved sensitivity to $\mathrm{NH}_{3}$ but also enhanced stability, reproducibility and fast response. This behavior can by ascribed to the synergy in the electrical properties of the three composing materials, as described before. Therefore, the results demonstrate the importance of adding GO to the PANI/ZnO platform, exploiting molecular combinations of three distinct materials in the same 
platform, which allowed the sensor operation at room temperature with fast response and high sensitivity.

\section{Conclusions}

Tetralayered LbL films could be produced with PANI, GO and $\mathrm{ZnO}$, with the presence of all components being confirmed with UV-vis. absorption and Raman spectroscopies. The number of tetralayers for the PANI/GO/PANI/ZnO architecture affected the electrical properties and morphology, according to impedance spectroscopy data and AFM images, respectively. The overall electrical resistance of the film decreased with the number of tetralayers owing to an increased amount of the conducting PANI. In contrast, film roughness increased with the number of tetralayers, as expected for nanostructured films. The roughness dependence, however, was not monotonic when exposure to $\mathrm{NH}_{3}$ was considered, since roughness decreased for PGPZ2T, increased for PGPZ4T, and remained practically constant for PGPZ3T. This indicates synergy in combining the materials properties, which was indeed confirmed by the higher performance of PGPZ3T for detecting $\mathrm{NH}_{3}$ in impedance spectroscopy measurements. The metrics of interest of the sensors made with the LbL films for use in monitoring working environments, namely limit of detection, response time and amplitude of response, were all adequate. Therefore, these PANI/GO/PANI/ZnO films can be considered as an alternative platform for room temperature $\mathrm{NH}_{3}$ sensors in which synergy is achieved upon combining distinct materials.

\section{Acknowledgements}

The authors thank the financial support from $\mathrm{CNPq}$ (141894/2013-0, 502391/2014-6), FAPESP (Grant numbers: 2012/23880-3, 2012/15543-7, 2013/14262-7, 2014/16789-5), CAPES, MCTI-SisNano and EMBRAPA from Brazil. The authors also thank Angelo L. Gobbi and Maria H. O. Piazzetta for their technical assistance in the microfabrication laboratory (LMF/LNNano-LNLS).

\section{References}

[1] P.-G. Su, L.-Y. Yang, NH3 gas sensor based on Pd/SnO2/RGO ternary composite operated at room-temperature, Sens. Actuators B Chem. 223 (2016) 202-208, http://dx.doi.org/10.1016/j.snb.2015.09.091.

[2] M. Hasan, M.O. Ansari, M.H. Cho, M. Lee, Electrical conductivity, optical property and ammonia sensing studies on $\mathrm{HCl}$ doped Au@polyaniline nanocomposites, Electron. Mater. Lett. 11 (2015) 1-6, http://dx.doi.org/10. 1007/s13391-014-4200-9.

[3] S. Cui, S. Mao, Z. Wen, J. Chang, Y. Zhang, J. Chen, Controllable synthesis of silver nanoparticle-decorated reduced graphene oxide hybrids for ammonia detection, Analyst 138 (2013) 2877, http://dx.doi.org/10.1039/c3an36922f.

[4] D.K. Bandgar, S.T. Navale, A.T. Mane, S.K. Gupta, D.K. Aswal, V.B. Patil, Ammonia sensing properties of polyaniline $/ \alpha-\mathrm{Fe} 2 \mathrm{O} 3$ hybrid nanocomposites, Synth. Metals 204 (2015) 1-9, http://dx.doi.org/10.1016/j.synthmet.2015.02. 032.

[5] S. Wagner, E. Angenendt, O. Beletskaya, J. Zeddies, Costs and benefits of ammonia and particulate matter abatement in German agriculture including interactions with greenhouse gas emissions, Agric. Syst. 141 (2015) 58-68, http://dx.doi.org/10.1016/j.agsy.2015.09.003.

[6] A.M. McQuilling, P.J. Adams, Semi-empirical process-based models for ammonia emissions from beef, swine, and poultry operations in the United States, Atmos. Environ. 120 (2015) 127-136, http://dx.doi.org/10.1016/j. atmosenv.2015.08.084.

[7] S. Bittman, K. Jones, R. Vingarzan, D.E. Hunt, S.C. Sheppard, J. Tait, et al., Weekly agricultural emissions and ambient concentrations of ammonia: validation of an emission inventory, Atmos. Environ. 113 (2015) 108-117. http://dx.doi.org/10.1016/j.atmosenv.2015.04.038.

[8] D.S. Correa, E.S. Medeiros, J.E. Oliveira, L.G. Paterno, L.H.C. Mattoso, Nanostructured conjugated polymers in chemical sensors: synthesis, properties and applications, J. Nanosci. Nanotechnol. 14 (2014) 6509-6527, http://dx.doi.org/10.1166/jnn.2014.9362.

[9] Y. Zhao, T.A. Shepherd, H. Li, H. Xin, Environmental assessment of three egg production systems - part I: monitoring system and indoor air quality, Poult Sci. 94 (2015) 518-533

[10] S. Ta, Y. Zhao, H. Li, S. Jp, H. Xin, Environmental assessment of three egg production systems - part II. Ammonia, greenhouse gas, and particulate matter emissions PubMed commons, Poult. Sci. 94 (2015) 534-543, http://dx doi.org/10.3382/ps/peu075.Full.

[11] S.B. Kondawar, P.T. Patil, S.P. Agrawal, Chemical vapour sensing properties of electrospun nanofibers of polyaniline/ZnO nanocomposites, Adv. Mater. Lett. 5 (2014) 389-395, http://dx.doi.org/10.5185/amlett.2014.amwc.1037.

[12] A.H. Navarchian, Z. Hasanzadeh, M. Joulazadeh, Effect of polymerization conditions on reaction yield, conductivity, and ammonia sensing of polyaniline, Adv. Polym. Technol. 32 (2013) 5-9, http://dx.doi.org/10.1002/ adv.21356.

[13] Guia Trabalista, NR 15 - Atividades e operações insalubres, Anexo XI Copyright $^{\mathscr{O}}$ 2003-2016 Portal Tributário Editora.

[14] M. Bendahan, P. Lauque, C. Lambert-Mauriat, H. Carchano, J.L. Seguin, Sputtered thin films of $\mathrm{CuBr}$ for ammonia microsensors: morphology, composition and ageing, Sens. Actuators B Chem. 84 (2002) 6-11, http://dx. doi.org/10.1016/S0925-4005(02)00004-7.

[15] D. Ponnusamy, S. Madanagurusamy, Porous anatase TiO2 thin films for NH3 vapour sensing, J. Electron. Mater. 44 (2015) 4726-4733, http://dx.doi.org/10. 1007/s11664-015-4099-4.

[16] Y. Jia, C. Yan, H. Yu, L. Chen, F. Dong, One-step fabrication of ammonia sensor by electrospinning PS- b -PMA nanofibers on quartz crystal microbalance, Sens. Actuators B Chem. 203 (2014) 459-464, http://dx.doi.org/10.1016/j.snb. 2014.06.018.

[17] S. Abdulla, T.L. Mathew, B. Pullithadathil, Highly sensitive, room temperature gas sensor based on polyaniline-multiwalled carbon nanotubes (PANI/MWCNTs) nanocomposite for trace-level ammonia detection, Sens. Actuators B Chem. 221 (2015) 1523-1534, http://dx.doi.org/10.1016/j.snb. 2015.08.002.

[18] B. Timmer, W. Olthuis, A. Van Den Berg, Ammonia sensors and their applications-a review, Sens. Actuators B Chem. 107 (2005) 666-677, http:// dx.doi.org/10.1016/j.snb.2004.11.054.

[19] X. Liu, S. Cheng, H. Liu, S. Hu, D. Zhang, H. Ning, A survey on gas sensing technology, Sensors 12 (2012) 9635-9665, http://dx.doi.org/10.3390/ s120709635.

[20] Z. Wu, X. Chen, S. Zhu, Z. Zhou, Y. Yao, W. Quan, et al., Enhanced sensitivity of ammonia sensor using graphene/polyaniline nanocomposite, Sens. Actuators B Chem. 178 (2013) 485-493, http://dx.doi.org/10.1016/j.snb.2013.01.014.

[21] Y. Li, B. Pathak, J. Nisar, Z. Qian, R. Ahuja, Metal-decorated graphene oxide for ammonia adsorption, EPL Europhys. Lett. 103 (2013) 28007, http://dx.doi.org/ 10.1209/0295-5075/103/28007.

[22] V. Talwar, O. Singh, R.C. Singh, ZnO assisted polyaniline nanofibers and its application as ammonia gas sensor, Sens. Actuators B Chem. 191 (2014) 276-282, http://dx.doi.org/10.1016/j.snb.2013.09.106.

[23] S.G. Pawar, M.A. Chougule, S.L. Patil, B.T. Raut, P.R. Godse, S. Sen, et al., Room temperature ammonia gas sensor based on polyaniline-TiO2 nanocomposite, IEEE Sens. J. 11 (2011) 3417-3423, http://dx.doi.org/10.1109/JSEN.2011. 2160392.

[24] U.V. Patil, N.S. Ramgir, N. Karmakar, A. Bhogale, A.K. Debnath, D.K. Aswal, et al., Room temperature ammonia sensor based on copper nanoparticle intercalated polyaniline nanocomposite thin films, Appl. Surf. Sci. 339 (2015) 69-74, http://dx.doi.org/10.1016/j.apsusc.2015.02.164.

[25] J.E. Oliveira, V.P. Scagion, V. Grassi, D.S. Correa, L.H.C. Mattoso, Modification of electrospun nylon nanofibers using layer-by-layer films for application in flow injection electronic tongue: detection of paraoxon pesticide in corn crop Sens. Actuators B Chem. 171-172 (2012) 249-255, http://dx.doi.org/10.1016/ j.snb.2012.03.056.

[26] A. Manzoli, F.M. Shimizu, L.A. Mercante, E.C. Paris, O.N. Oliveira, D.S. Correa, et al., Layer-by-layer fabrication of AgCl-PANI hybrid nanocomposite films for electronic tongues, Phys. Chem. Chem. Phys. 16 (2014) 24275-24281, http:// dx.doi.org/10.1039/C4CP04150J.

[27] F.N. Crespilho, V. Zucolotto, O.N. Oliveira, F.C. Nart, Electrochemistry of layer-by-layer films: a review, Int. J. Electrochem. Sci. 1 (2006) 194-214.

[28] Y. Lvov, H. Haas, G. Decher, H. Moehwald, A. Kalachev, Assembly of polyelectrolyte molecular films onto plasma-treated glass, J. Phys. Chem. 97 (1993) 12835-12841, http://dx.doi.org/10.1021/j100151a033.

[29] G. Decher, J.-D. Hong, Buildup of ultrathin multilayer films by a self-assembly process 1 consecutive adsorption of anionic and cationic bipolar amphiphiles on charged surfaces, Makromol. Chem. Macromol. Symp. 46 (1991) 321-327, http://dx.doi.org/10.1002/masy.19910460145.

[30] G. Decher, Fuzzy nanoassemblies: toward layered polymeric multicomposites, Science 277 (80) (1997) 1232-1237, http://dx.doi.org/10. 1126/science.277.5330.1232.

[31] J. Chen, J. Yang, X. Yan, Q. Xue, $\mathrm{NH} 3$ and $\mathrm{HCl}$ sensing characteristics of polyaniline nanofibers deposited on commercial ceramic substrates using interfacial polymerization, Synth. Metals 160 (2010) 2452-2458, http://dx. doi.org/10.1016/j.synthmet.2010.09.026.

[32] M.P. Prabhakaran, L. Ghasemi-Mobarakeh, G. Jin, S. Ramakrishna, Electrospun conducting polymer nanofibers and electrical stimulation of nerve stem cells, J. Biosci. Bioeng. 112 (2011) 501-507, http://dx.doi.org/10.1016/j.jbiosc.2011. 07.010.

[33] Y. Zhang, G.C. Rutledge, Electrical conductivity of electrospun polyaniline and polyaniline-blend fibers and mats, Macromolecules 45 (2012) 4238-4246, http://dx.doi.org/10.1021/ma3005982.

[34] S. Valiavalappil, S. Harinipriya, Electrically conducting nylon 6, 6-polyaniline short composite fibres synthesised by the solvent coagulation method, Synth. Metals 162 (2012) 2027-2032, http://dx.doi.org/10.1016/j.synthmet.2012.10. 008 . 
[35] C. Van Tuan, M.A. Tuan, N. Van Hieu, T. Trung, Electrochemical synthesis of polyaniline nanowires on Pt interdigitated microelectrode for room temperature NH3 gas sensor application, Curr. Appl. Phys. 12 (2012) 1011-1016, http://dx.doi.org/10.1016/j.cap.2011.12.006.

[36] A. de Barros, M. Ferreira, C.J.L. Constantino, M. Ferreira, Nanocomposites based on LbL films of polyaniline and sodium montmorillonite clay, Synth. Metals 197 (2014) 119-125, http://dx.doi.org/10.1016/j.synthmet.2014.09.001.

[37] C. Steffens, A. Manzoli, J.E. Oliveira, F.L. Leite, D.S. Correa, P.S.P. Herrmann, Bio-inspired sensor for insect pheromone analysis based on polyaniline functionalized AFM cantilever sensor, Sens. Actuators B Chem. 191 (2014) 643-649, http://dx.doi.org/10.1016/j.snb.2013.10.053.

[38] C.-F. Li, C.-Y. Hsu, Y.-Y. Li, NH3 sensing properties of ZnO thin films prepared via sol-gel method, J. Alloys Compd. 606 (2014) 27-31, http://dx.doi.org/10. 1016/j.jallcom.2014.03.120.

[39] M. Khairy, Polyaniline-Zn0.2Mn0.8 Fe2O4 ferrite core-shell composite: preparation, characterization and properties, J. Alloys Compd. 608 (2014) 283-291, http://dx.doi.org/10.1016/j.jallcom.2014.04.130.

[40] M. Sharma, P. Jeevanandam, Synthesis characterization and studies on optical properties of indium doped ZnO, Nanoparticles 53 (2014) 561-565.

[41] S.R. Anton, H.A. Sodano, A review of power harvesting using piezoelectric materials (2003-2006), Smart Mater. Struct. 16 (2007) R1-R21, http://dx.doi. org/10.1088/0964-1726/16/3/R01.

[42] S.S. Varghese, S. Lonkar, K.K. Singh, S. Swaminathan, A. Abdala, Recent advances in graphene based gas sensors, Sens. Actuators B Chem. 218 (2015) 160-183, http://dx.doi.org/10.1016/j.snb.2015.04.062.

[43] S. Gayathri, P. Jayabal, M. Kottaisamy, V. Ramakrishnan, Synthesis of ZnO decorated graphene nanocomposite for enhanced photocatalytic properties, J. Appl. Phys. 115 (2014) 179504, http://dx.doi.org/10.1063/1.4874877.

[44] X. He, L.-l. Wu, J. -j. Wang, T. Zhang, H. Sun, N. Shuai, Layer-by-layer assembly deposition of graphene oxide on poly(lactic acid) films to improve the barrier properties, High Perform. Polym. 27 (2015) 318-325, http://dx.doi. org/10.1177/0954008314545978.

[45] R.S. Andre, A. Pavinatto, L. a. Mercante, E.C. Paris, L.H.C. Mattoso, D.S. Correa, Improving the electrochemical properties of polyamide 6/polyaniline electrospun nanofibers by surface modification with ZnO nanoparticles, RSC Adv. 5 (2015) 73875-73881, http://dx.doi.org/10.1039/C5RA15588F.

[46] J. William, S. Hummers, R.E. Offeman, Preparation of graphitic oxide, J. Am. Chem. Soc. 80 (1958) 1339, http://dx.doi.org/10.1021/ja01539a017.

[47] N.I. Kovtyukhova, P.J. Ollivier, B.R. Martin, T.E. Mallouk, S.A. Chizhik, E.V. Buzaneva, et al., Layer-by-layer assembly of ultrathin composite films from micron-sized graphite oxide sheets and polycations, Chem. Mater. 11 (1999) 771-778, http://dx.doi.org/10.1021/cm981085u.

[48] X. Huang, N. Hu, R. Gao, Y. Yu, Y. Wang, Z. Yang, et al., Reduced graphene oxide-polyaniline hybrid: preparation, characterization and its applications for ammonia gas sensing, J. Mater. Chem. 22 (2012) 22488, http://dx.doi.org/ 10.1039/c2jm34340a.

[49] A.G. Milekhin, N.A. Yeryukov, L.L. Sveshnikova, T.A. Duda, E.I. Zenkevich, S.S. Kosolobov, et al., Surface enhanced Raman scattering of light by ZnO nanostructures, J. Exp. Theor. Phys. 113 (2011) 983-991, http://dx.doi.org/10 1134/S1063776111140184.

[50] Y. Zhao, H. Xin, T. Shepherd, Thermal environment, ammonia concentrations, and ammonia emissions of aviary houses with white laying hens, Trans. ASABE 56 (2013) 1145-1156, http://dx.doi.org/10.13031/trans.56.10097.

[51] J.A.D. Barbosa Filho, M.L.V. Queiroz, D. de, F. Brasil, F.M.C. Vieira, I.J.O. Silva, Transport of broilers: load microclimate during Brazilian summer, Eng. Agrícola. 34 (2014) 405-412, http://dx.doi.org/10.1590/S010069162014000300003.
[52] C. Wang, L. Yin, L. Zhang, D. Xiang, R. Gao, Metal oxide gas sensors: sensitivity and influencing factors, Sensors 10 (2010) 2088-2106, http://dx.doi.org/10. 3390/s100302088.

[53] G.F. Fine, L.M. Cavanagh, A. Afonja, R. Binions, Metal oxide semi-conductor gas sensors in environmental monitoring, Sensors 10 (2010) 5469-5502, http:// dx.doi.org/10.3390/s100605469.

[54] G. Korotcenkov, S.H. Han, B.K. Cho, Material design for metal oxide chemiresistive gas sensors, J. Sens. Sci. Technol. 22 (2013) 1-17, http://dx.doi. org/10.5369/JSST.2013.22.1.1.

[55] T.-Y. Chen, H.-I. Chen, C.-S. Hsu, C.-C. Huang, J.-S. Wu, P.-C. Chou, et al., Characteristics of $\mathrm{ZnO}$ nanorods-based ammonia gas sensors with a cross-linked configuration, Sens. Actuators B Chem. 221 (2015) 491-498, http://dx.doi.org/10.1016/j.snb.2015.06.122.

[56] S. Yoo, X. Li, Y. Wu, W. Liu, X. Wang, W. Yi, Ammonia gas detection by tannic acid functionalized and reduced graphene oxide at room temperature, J. Nanomater. 2014 (2014) 1-6, http://dx.doi.org/10.1155/2014/497384.

[57] O.N. Oliveira Jr, T.A.T. Neves, F.V. Paulovich, M.C.F. de Oliveira, Where chemical sensors may assist in clinical diagnosis exploring big data, Chem. Lett. 43 (2014) 1672-1679, http://dx.doi.org/10.1246/cl.140762.

[58] F.V. Paulovich, M.L. Moraes, R.M. Maki, M. Ferreira, O.N. Oliveira, M.C.F. de Oliveira, Information visualization techniques for sensing and biosensing, Analyst 136 (2011) 1344-1350, http://dx.doi.org/10.1039/c0an00822b.

[59] M.L. Moraes, L. Petri, V. Oliveira, C.A. Olivati, M.C.F. De Oliveira, F.V. Paulovich, et al., Detection of glucose and triglycerides using information visualization methods to process impedance spectroscopy data, Sens. Actuators B Chem. 166-167 (2012) 231-238, http://dx.doi.org/10.1016/j.snb.2012.02.046.

[60] S. Ji, Y. Li, M. Yang, Gas sensing properties of a composite composed of electrospun poly(methyl methacrylate) nanofibers and in situ polymerized polyaniline, Sens. Actuators B Chem. 133 (2008) 644-649, http://dx.doi.org/ 10.1016/j.snb.2008.03.040.

[61] G.D. Khuspe, S.T. Navale, D.K. Bandgar, R.D. Sakhare, M.A. Chougule, V.B. Patil, SnO2 nanoparticles-modified polyaniline films as highly selective, sensitive, reproducible and stable ammonia sensors, Electron. Mater. Lett. 10 (2014) 191-197, http://dx.doi.org/10.1007/s13391-013-3096-0.

[62] Y. Yang, X. Yang, W. Yang, S. Li, J. Xu, Y. Jiang, Porous conducting polymer and reduced graphene oxide nanocomposites for room temperature gas detection, RSC Adv. 4 (2014) 42546-42553, http://dx.doi.org/10.1039/C4RA06560C.

[63] C. Xiang, D. Jiang, Y. Zou, H. Chu, S. Qiu, H. Zhang, et al., Ammonia sensor based on polypyrrole-graphene nanocomposite decorated with titania nanoparticles, Ceram. Int. 41 (2015) 6432-6438, http://dx.doi.org/10.1016/j. ceramint.2015.01.081.

[64] D.K. Bandgar, S.T. Navale, M. Naushad, R.S. Mane, F.J. Stadler, V.B. Patil, Ultra-sensitive polyaniline-iron oxide nanocomposite room temperature flexible ammonia sensor, RSC Adv. 5 (2015) 68964-68971, http://dx.doi.org/ 10.1039/C5RA11512D.

[65] Y. Li, H. Ban, M. Yang, Highly sensitive $\mathrm{NH}_{3}$ gas sensors based on novel polypyrrole-coated $\mathrm{SnO}_{2}$ nanosheet nanocomposites, Sens. Actuators B Chem. 224 (2015) 449-457, http://dx.doi.org/10.1016/j.snb.2015.10.078.

[66] S. Bai, Y. Tian, M. Cui, J. Sun, Y. Tian, R. Luo, Polyaniline@SnO 2 heterojunction loading on flexible PET thin film for detection of $\mathrm{NH}_{3}$ at room temperature, Sens. Actuators B Chem. 226 (2016) 540-547, http://dx.doi.org/10.1016/j.snb. 2015.12.007 